\title{
Excessive Faith in Certainty and Its Public Proponents in the Non-linear Uncertain World: Reasons and ... More Reasons
} HEFFERNAN M. (2021) UNCHARTED: HOW UNCERTAINTY CAN POWER CHANGE. LONDON: SIMON \&
SCHUSTER. 373 P. ISBN 978-1-4711-7982-2

\author{
Irina Trotsuk \\ Doctor of Sociological Sciences, Professor, Sociology Chair, RUDN University \\ Leading Research Fellow, Center for Fundamental Sociology, HSE University \\ Address: Miklukho-Malaya str., 6, Moscow, Russian Federation 117198 \\ E-mail: irina.trotsuk@yandex.ru
}

Being a sociologist gives you the right (or privilege) to broaden your readings far beyond "purely" scientific works. There are at least two legitimate reasons for not being too choosy: on the one hand, sociologists need to get out of their "ivory towers" in order to interpret their scientific findings correctly (popular non-fiction provides a better understanding of social representations and beliefs), while on the other hand, sociologists are often reproached for being too theoretical and for missing (or deliberately omitting) practical points (popular non-fiction provides an insight into the work of practitioners we design and conduct our research for). The current pandemic (for the foreseeable future, we will be mentioning COVID-19 as a reference point) undermined the expert claims of science in general, not to mention the social sciences that have always been criticized for being not scientific enough as too subjective and too value-loaded. Today, even natural sciences are hit by criticism from all sides: it is one thing that we still cannot travel in space, which is of little importance for our everyday life, while it is quite another thing that you do not know how to recover from a new illness which is either a nontypical flu not to be too scared of or a new "plague" of our time to be terrified of. The mass media, governments, and experts (even previously trusted ones) do not provide clear recommendations on what to do, change their recommendations all the time, quarrel in indecent debates on TV shows, and constantly accuse, fine, and punish you for doing something wrong in your private life without providing clear and convincing (scientifically and rhetorically) explanations on what is right to do.

Such an intervention by the state and other public institutions has changed the demarcation line between public and private. The state considers this intervention its privilege

* The results of the project "Ethics of Solidarity and the Biopolitics of Quarantine: Theoretical Problems of the Cultural and Political Transformations during Pandemic", carried out within the framework of the Basic Research Program at the National Research University Higher School of Economics (HSE University) in 2021, are presented in this work. 
to make decisions on how you must behave and what you must do under the pandemic in your private life, on whom you can meet and under what conditions, on when you are defined as an infected and social threat, and so on. However, people do not consider such a control of their private life (safety measures, relations with dear ones, free-time choices, or preferences in health practices) as a one-sided path on which only public institutions have the right to question, instruct, and punish. Public opinion demands clearer reports on the reasons and grounds for decisions and measures from institutions and their representatives, and, if not provided with unambiguous and trustworthy ones, prefers to reproach, oppose, protest, or ignore the newly set rules and restrictions, regardless of the consequences.

Furthermore, people started to question those public events that have been indisputable for support, but today, the costs of these events to the public are reconsidered as affecting their private well-being. For instance, flights to the International Space Station have been a national source of pride in Russia since the launch of the Soviet spaceship program. However, when a Russian film crew spent some time in October at the International Space Station to film scenes for the first movie shot in space, Russians did not support this flight with the happiness and solidarity as expected, and questioned the need and legitimacy of spending so much money on this flight instead of buying extremely expensive medicines, financing the post-COVID-19 rehabilitation, and so on.

The main issues are certainly not so much a new, unfamiliar intersection of public and private under the pandemic, the new measures transforming everyday life, including familiar practices and freedoms, or the blurring of the distinction between private and public as if sanctioned by the pandemic, all of which affect the very foundations of contemporary societies and "privacy". It is rather the issue that underlines all these changes, that is, a bright new (in terms of scale and impact) uncertainty that is both objective (no one can predict when the COVID-19 pandemic will turn into a kind of the annual, seasonal, predictable, and non-fatal flu epidemic) and subjective (no one can be sure of anything under such an objective uncertainty).

According to its praises on the cover, the reviewed book of the

... distinguished businesswoman and author Margaret Heffernan explores the people and organizations who aren't daunted by uncertainty. Ranging freely through history and from business to science, government to friendship [perhaps, sometimes too freely even for non-fiction], this . . book challenges us to resist the false promises of technology and efficiency and instead to mine our own creativity and humanity for the capacity to create the futures we want and can believe in. A new chapter, written in the light of the pandemic, shows how and where uncertainty can drive, even accelerate, positive change.

It is doubtful that the current situation can be defined in such an optimistic perspective, but the author indeed mentions the COVID-19 pandemic only in the last additional chapter, thus, not speculating on the topic at all. It is even more doubtful that the author 
can be called the "Karl Popper for the 21st century", though the book is definitely worth reading.

This work is not only, as they say, thought-provoking, but is also good additional reading for sociologists who want to grasp the idea of total social interconnectedness, the usefulness of the case study as both research strategy and practical guide, and the everyday implications of difficult notions (prediction, freedom, technology, certainty, etc.), i.e., the book is a good "device" for broadening the sociological imagination. The book presents a range of topics that are clearly indicated, explained, and illustrated by convincing examples in a humanistic and optimistic manner. Let us briefly go through these topics.

First, it is our unchanging, passionate, and literally manic concern for the future and its prediction which makes even the news "mostly speculation: what will happen ... Entire industries - property, travel, banks, insurance, pensions, technologies - analyze, construct and sell permutations of the future ... We have come to expect the future to be minutely and perfectly predictable ... But the predictability of life, on which we've come to depend, seems to fall away and we're left angry, intolerant, fearful" (12).

In the first part, Heffernan explains how our favorite models for predicting the future let us down, and starts with the commercialization of prediction "services". First astrology became a big commercial business, but it was the financial markets that turned forecasting into a big, important industry by "selling reassurance, inspiration and advice" on the future in order to eliminate "the pain of uncertainty or alleviate it" (16). In the early 20 th century, technology just provided the tools to make forecasting scientific (at least to look scientific), freed economics from "physics envy", and allowed entrepreneurs and statisticians to capture the complexity of economic markets by calculating correlations and identifying measurable patterns. The problem was that this scientific approach was based either on deduction; pundits "applied their theories to mountains of data in the belief that their efforts would elucidate patterns that predicted the future" $(20)$ - or on induction, i.e., "forecasting by analogy, believing that history repeated itself, albeit imperfectly" (21). As history has proven, such economic forecasts were blindsided, and the most successful pioneers of economic forecasts were just lucky: “They had more faith than skill, imbuing their theories and data with the certainty and consolidation they craved. They imagined themselves objective scientists uncovering laws about markets as absolute and reliable as the laws of physics and believed that financial numbers unambiguously revealed immutable scientific truths" (23). This reminds of the competing scientific calculations of the future of the COVID-19 pandemic, which is often wrong as based on biased beliefs or irrelevant criteria for collecting, analyzing, and comparing data.

The pioneers of commercialized forecasting "discovered three profound problems endemic to forecasts that dog them still today [and in the global fight against the COVID-19]: forecasts are incomplete, ideological and self-interested" (23). The first problem is the models we use - they are too simplified versions of the part of reality under study, which means subjective choices of data and tools. "Models will always be subjective and incomplete representations of complex reality" (24), but the state and its institutions ignore this 
limitation and continue to produce new and more simplified models, automate them to the limit and trust their results as the final and undeniable truth.

The second problem is "agendas ... cherished, implicit beliefs about how the world works, about what mattered and what did not, i.e., ideologies" (Ibid.). People rarely acknowledge that their "mental model is an ideology and that forecasts always contain an agenda" (25); in addition, the early forecasting businesses as commercial enterprises had to rely on the preferences and priorities of their customers. The author writes that "Economists could never be impartial observers [like scientists today, which affects the course of the COVID-19 pandemic]. Their models are profoundly susceptible to the beliefs of the human beings who design and run them; they aren't and cannot be morally neutral [the intervention of personal beliefs and experience into expert assessments has affected the outcomes of the COVID-19 pandemic]" (26). Experts often cannot and do not want to remain dispassionate despite the implicit public requirement "to treat everything ... as problems to be solved with detachment and objectivity".

Moreover, experts can neither make policymakers follow their instructions nor control how policymakers implement them, i.e., "experts can advise policymakers on what to do, but they may find their advice taken in ways that were never intended". ${ }^{2}$ Certainly, policymakers can intervene and influence what happen next to the expertise - to the better (by restraining private claims in public sphere) or to the worse (by supporting mistaken beliefs or harmful ideas). However, power (of position or expertise) tends to make its owners hostages of their ideologies - "mental models of how the world works" ("conceptual boxes"). Thus,

They cleave to what they know and are loyal to the grandeur and power of their big ideas - sticking to them often in the face of overwhelming evidence" [this explains the unshakable confidence of antivaxers and flat-earthers]. The only thing that cannot be denied, especially under the pandemic, is that "human discomfort with uncertainty, together with a craving for reassurance, has fueled an industry [of expertise, forecasting and consulting] that enriches itself by terrorizing us with uncertainty and taunting us with certainty. (26)

The third problem of forecasts is that they easily turn from prediction to propaganda, and "recruit us into an army of believers" by implicitly eliminating possible pragmatic questions about limitations and implications of future inventions with the dramatic and confident "rhetoric of inevitability". Heffernan provides confirmations, such as the lack of questions about the impact of artificial intelligence on the labor market, civil liberties (who owns the data and for what purposes, or what aspects of our existence as aggregations of data can be standardized and measured) ${ }^{3}$, public transportation, and so on. She

1. Nichols T. (2017) The Death of Expertise: The Campaign against Established Knowledge and Why It Matters, New York: Oxford University Press, p. 64.

2. Ibid., p. 223.

3. See, e.g., O’Neill C. (2016) Weapons of Math Destruction: How Big Data Increases Inequality and Threatens Democracy, New York: Crown Publishers. 
says "The more we believe, the less we question, the more probable the forecast becomes. A simplistic commercial view of the future is being forced onto a world as though there are no alternative possibilities, when in fact there are many" (33). The author's explanation is simple and pessimistic:

\begin{abstract}
Promising improbable benefits, the propagandists exploit one enormous advantage: ignorance. The future hasn't happened yet, so we can't be completely certain that they are wrong. But that's no reason to swallow whatever we're told, sold or dazzled by. It's a good reason to ask better questions. That is what some research firms [especially good sociological ones] hope their forecasts can generate: not numbing certainty, but deeper, more exploratory thinking and debate. A prediction is really a hypothesis [just like conclusions from sociological data and research]. (34)
\end{abstract}

In general, Heffernan contributes to the "death of expertise" by insisting, in essence, on a universal right to question forecasts and to experiment. Unlike Nicholson, who argues that non-experts are often too confident in their abilities to judge and make decisions while being absolutely ignorant of the matter, Heffernan believes that non-experts underuse their right to question expert assessments. She seems to support Nicholson's argument that people "immediately complain that any assertion of expertise from an actual expert is nothing more than fallacious 'appeals to authority', sure signs of dreadful 'elitism', and an obvious effort to use credentials to stifle the dialogue required by a 'real' democracy". ${ }^{4}$ However, it is not on the grounds that experts stay in "ivory towers" of scientific terminology with "equals" in knowledge and rigor, but rather emphasizing another of Nicholson's ideas that technology and science do not increase certainty about the world. Heffernan refers to Popper's idea about the general growth of knowledge as a driver of progress and an antidote to authoritarianism, while Nicholson mentions Popper's idea that science is built on shifting sands, and that scientists must revise even the most cherished theories and beliefs.

Second, it is our passionate and endless faith in the omnipotent technology: "Today's technology may be the most advanced the world has ever seen, but it is imperfect: incomplete, biased and full of error ... Artificial intelligence trusts correlations that turn out to be irrelevant, selective or ill-informed" (2). The problem is not technology itself, but the way we use it as the only source of true and objective (free from subjective biases) data. We forget or ignore the fact that we are still designers and users of technology, which makes it as erroneous as we are mistaken. Every sociology teacher of the SPSS knows that students often make it calculate average values and other statistics for nominal scales, which is meaningless and absurd for the scale just coded with numbers.

Heffernan identifies the following challenges of "our utopian fantasy of the tech industry" (6-7): it is an erroneous belief "that all the data in the world will yield perfect predictions" (predictive systems are frequently wrong, which is obvious from trivial or irrelevant recommendations that we all get in the Internet); the high costs of the strong

4. Ibid., p. 5 . 
dependence on technology - when outsourcing to machines what we can do ourselves, we contribute to the automation paradox, i.e., we lose those skills that we automate and become increasingly dependent on machines (for instance, GPS is a great device, but it makes us think less, our memory shrinks, our neighborhood becomes less familiar, and the very search task becomes a source of anxiety); and technology helps us by "force-fitting a predetermined model onto the surprising variety of human existence, but absolute certainty about all aspects of our life would be tyranny".

Today, under the pandemic that the state wants to control, we witness that technology reduces us to selective subsets of the available data, and ignores everything else about us and about people who were not selected to be turned into datasets. Therefore, technology in general and automatization in particular "merely speed up bias, errors, short-term thinking and flaky assumptions" (78). For instance, today's popular "profiling and assessment technologies are a cheap, fast way to weed through thousands of resumes. But ... they feed off and look for stereotypes: simplistic, reductive versions of whole people ... Simplified models of complex individuals encourage us to view one another as objects, types, commodities measured by benchmarks we can't see and did not define" (80). Simplified models do not help us make good decisions and the right predictions. Heffernan provides a disturbing example - since the uncertainty and ambiguity implicit in DNA data make it hard to use for rational and safe decision-making in gene-editing and genealtering "improving" technologies, who would decide on what to eliminate or amplify (state-mandated definitions in authoritarian regimes or market decisions increasing inequality)? Can we be sure that removing flaws to reduce uncertainty would not deprive us of qualities and traits the future would need?

Third, it is our striking desire for estimating, planning, managing and anticipating (for control in general) in order to reduce "ineradicable uncertainty inherent to human life" (2). She writes that "The entire construct of management - forecast, plan, execute hinges our capacity to make well informed estimates ... We have moved from a complicated world to a complex one... Complicated environments are linear, follow rules and are predictable; like an assembly line, they can be planned, managed, repeated and controlled ... But the advent of globalization, coupled with pervasive communications, has made much of life complex: non-linear and fluid, where very small effects may produce disproportionate impacts" (3). Heffernan considers scenario planning as a replacement for traditional planning which became dangerously ineffective under the today's complexity and uncertainty with too many assumptions and risks. Scenarios combine "hard data" (rigorously researched and reliable datasets) and "soft data" (cultural differences), focusing less on predicting outcomes and more on illuminating the factors at work. Scenarios must be relevant and challenging, pragmatic, and not ideological; "like life, they are bound to be messy, patchy, full of paradox and contradictions [it is doubtful that policymakers would accept such features for their management and development scenarios]" (156). Heffernan identifies a problem of scenario planning in that it becomes

5. See, e.g., Zuboff Sh. (2019) The Age of Surveillance Capitalism: The Fight for a Human Future at the New Frontier of Power, London: Profile Books. 
technocratic and dependent on artificial intelligence as the key: "Once quantified, scenarios can become the enemy of thought . . . too rigid and their makers so wedded to them as to become blind to disconfirming data; numbers acquire more authority than they deserve" (159).

Therefore, institutions ignore our non-standardized and non-quantified demands, we ignore institutional requirements, and both ignore, albeit for different reasons, that "complex global systems incorporate a multitude of factors, each influencing others but controlled by no one person or nation. We used to ignore these systems but their problems have become ours now, when a bank halfway across the world crashes or a government falls" (4). As throughout the book, the author provides here the convincing example of Apple's iPhone because its production depends on raw materials and suppliers from many countries. This complex supply chain satisfies both the states (taxes and employment) and the consumer (cheaper iPhones), while "exposing Apple (and similar phone manufacturers) to natural disasters, labor disputes, economic volatility, social turmoil, religious strife, trade wars and political discontent: all factors over which the company has no control, little influence and poor foresight" (4).

Thus,

in our hunger to know the future, is the alleviation of doubt and uncertainty sufficient reward for the loss of agency, of autonomy, . . . of social connection and diversity ... In the utopian picture of predictable lives, we don't need compassion, generosity or trust, ... there are no flukes, no happy (or unhappy) accidents . . . Trusting a single approach [total technological control] is always dangerous, but living with incomplete knowledge doesn't leave us useless or passive ... Surrendering agency, action and adventure for convenience is a miserable bargain. (102-103)

In the second part of the book, Heffernan insists that small actions can make a disproportionate impact in the complex systems we live in, that we need such actions in the highly dynamic social systems in which theories of change might purport to offer certainty but often prove illusory, and that we need experiments to explore the boundaries of the possible.

The author prefers a broader interpretation of experiment as "a pragmatic way to test out the future", to "explore the ecosystem, the boundaries of which you can't quite discern"; "to have real impact, other people must know about experiments and be able to contribute" (112). This contribution is questionable due to many personal reasons (lack of knowledge, desire, time, intentions, etc.) and public rules - the state and its institutions, especially in Russia, do not have a habit of inviting ordinary people to become informed participants of experiments that change their life. Many people are used to being controlled because they "think that change has to come wholesale from the top" and refuse to exercise one's agency. ${ }^{6}$ Heffernan argues that "we start to map our future when we dare to experiment with the present (but do not start with a clean slate), when we don't 
make ourselves hostage to the past or to the salesmen of determinism and machines ... Instead of abdicating the future to those who know no more than we do, experiments are bolder, enlisting every kind of imagination in pursuit of more options. They show us what we miss when we cling to the shore, pinioned by forecasts or orthodoxies, doubt or fear" (148-149).

This is an inspiring description of the possible future, but it poses questions about the costs of experiments and who is to pay them, about those people who refuse to accept experiments or to participate in them, about those institutions and spheres of life that would not survive experiments and do not need them, and about who would decide on the aims, strategies, timing, and participants of experiments. Sometimes people misuse the term "experiment", which is one of the reasons for the low anti-COVID-19 vaccination rate in Russia compared to many European countries: people believe that the new vaccines were not tested enough to be safe both today and in the future (unknown longterm consequences), and call them an "experiment", both medical and social. The latter is explained by the contradiction in the state discourse: on the one hand, the Russian government denies the necessity of the direct compulsory vaccination in legislation as violating individual rights, while on the other hand, the government supports the regional and local authorities' decisions to selectively (in fact, rather generally) introduce compulsory vaccination (as a condition for employment in some industries or for accessing certain public services) in order to protect the society by increasing the share of the vaccinated population. $^{7}$

Heffernan provides another example of the enforced experiment under the current pandemic, writing that "almost overnight, it seemed, companies that had long resisted flexible working (a charter for slackers, some thought) moved large parts of their workforce to working from home" (328) which often increased productivity and mutual trust, exploded frequent two-way communication, and flattened hierarchies. However, "many executives went back to thinking, talking, dreaming about a return to normal. They continued to see the pandemic as an interruption" (329). Certainly, there are many advantages in distant and flexible working, but only if you can arrange a proper part of your private housing space for such public activities. For many people, this is a very difficult, tiresome, and exhausting option, and they are not ready for further experiments on mixing their private and public lives. Heffernan provides many other examples of decisionmakers "up to their necks in a status quo trap, believing that a well-measured if scary present is less risky than an ambiguous future" (199). It is not only decision-makers, but also people without power often refuse to change and to be responsible for outcomes and consequences when the status quo is considered "normal", "bearable" or "good enough".

Fourth, it is freedom as the most needed instrument for forging our identity and our future today when "we have huge decisions to make - about the climate, about tech-

7. See, e.g., Giubilini A., Savulescu J. (2019) Vaccination, Risks, and Freedom: The Seat Belt Analogy. Public Health Ethics, vol. 12, no 3, pp. 237-249; Gravagna K., Becker A., Valeris-Chacin R., Mohammed I., Tambe S., Awan F. A., Toomey T. L., Bastae N. E. (2020) Global Assessment of National Mandatory Vaccination Policies and Consequences of Non-compliance. Vaccine, vol. 38, no 49, pp. 7865-7873. 
nology, capitalism, democracy" (7). Heffernan refers to Popper's idea that the growth of knowledge is the fundamental driver of all human progress, i.e., history can neither repeat itself nor be a predictor. She does not deny the teaching ability of history, but argues that "the lessons we drew weren't the right lessons", because we think in analogies and ignore "the differences between events and open exposure to accident and contingency" (55). Thus, "when the Arab Spring began in Tunisia in December 2010, analogies popped up like daisies (European revolutions of 1848 , the Prague Spring anti-Communist rising of 1968, and the fall of the Berlin Wall)" because "the belief that history repeats itself often leads people to think that it is their own history that is being repeated - but not someone's else's... It is a very human error to assume that countries, peoples and histories we don't know very well must be similar to our own and to conflate their history with ours" (55-56). She continues, saying that "History can't offer recipes but it can provide raw material with which to construct fresh combinations, drawn from where we have been, where we are today and where we wish to be tomorrow". The fact that history "offers neither inevitability nor guarantees isn't its weakness but its greatest power" (64), which provides us with freedom of choice.

Heffernan sums up all four points as factors determining our endless search for sources of certainty, mainly by pundits, those "experts and forecasters who claim superior knowledge". However, the study of their track records for twenty years showed that they rarely were happy enough to guess the right path. ${ }^{8}$ In general, the main source of false predictions is unsatisfactory modeling that misses important factors for the valued simplicity and accountability, makes attribution errors, uses inadequate data, and prefers aesthetically-pleasing analogies to critical differences. Our reliance on technology is not a decision:

Technology offers a newer, shinier model, purporting to provide certainty, while in fact merely masking ambiguities ... Algorithms are opinions encoded in numbers. They impose subjective assumptions on data that's skewed and incomplete [a good example is the difference in Russia's positions in rankings of the COVID-19 mortality rate due to the differing criteria for qualifying deaths]. Unique or rare external events may render what was formerly predictable suddenly unforeseeable, making historical data [which we love to refer to] irrelevant or useless (this is frequently true of epidemics). (6)

Thus, this is not a scientific book, but a good sociological reading. One may say that there is nothing new in the book, and a good student can read much more scientific works to learn about exactly the same things with more reliable data, references, and explanations. Such criticism is fair, but the book is a good first reading to "see" the interconnections of the key problems of our time in a clear narrative with convincing cases from past and present, science and business, institutional interaction and everyday life. Some difficult sociological issues are explained clearly and easily, for instance, the biographical

8. See, e.g., Tetlock Ph., Gardner D. (2016) Superforecasting: The Art and Science of Prediction, New York: Random House. 
method (though it is not mentioned as such). She writes here that "Memory serves many functions - and one of them is to allow us to simulate the future... The fluidity of our memory isn't always negative. It allows us to be more flexible, adaptable and creative in our thinking" (44-45). Another example is the author's implicit criticism of the narrative approach to life as preventing "a lively, free-flowing combination of routine and creativity, knowledge and improvisation": "The narrative approach argues, in essence, that each of us constructs a narrative and sticks to its plot and characterization. In the same way that forecasters persuade by constructing a compelling story, strong narratives can become a trap too, constraining and limiting how we see ourselves and other people. Instead of illuminating freedoms, choices and imagination, narrative proposes that we are slaves to plots we can't know and didn't write" $(45){ }^{9}$

Finally, it is necessary to mention what the book is missing (not shortcomings but rather features the reader should be ready for). The author's narrative is humanistic, and denies apathy or resignation as our possible choices. There is no doubt that we should reject "pundits and propagandists of determinism ... to explore the contours and landscape of possibility ..., to be bolder in our search, more penetrating in our enquiry, more energetic in our quest for discovery" ( 7 ). Certainly, there is no sense in clinging to determinism (social-historical, economic, cultural, technological, etc.) in the world in which simple, linear trends of development ceased to dominate; however, new theories explaining new forms of nonlinear change and development ${ }^{10}$ are not too encouraging or inspiring. Thus, Heffernan presents a too-optimistic and even utopian perspective: there are too many objective restrictions and limitations in contemporary society to agree that every person or nation has a choice at all not to mention the choice "between surrender or participation" (7). "Genius and creativity in preparation" together with "an infinite mandate to explore" and "methodology that progresses with questions" (8) are great things, but, unfortunately, underrepresented in society: a complex, non-linear world permeated with ideologies and itineraries deprives its passionate reformers of a developed imagination and fighting spirit. One of restraining factors is mentioned in the Introduction, where the author writes that "we are deluged with propaganda undermining human talents in favor of the perfection of machines" (9). Thus, the state invests too much money in technology for social control to give up this propaganda, i.e., new generations are born into and socialized in the world based on technology which they perceive as legitimate and normal.

Another implicit pessimistic feature of this optimistic book is that the reader cannot but ask the same question throughout the reading: if people have choice, creativity, passion, and the ability to contribute to positive changes for a better world, why do we still live in the increasingly technologized and dehumanized world? If we know that strictly-linear, command-and-control stories do not work, like expertise without the glue of social capital, why did governments choose both of the wrong approaches to fight the

9. See also Bauman Z. (2001) The Individualized Society, Cambridge: Polity.

10. See, e.g., Deleuze G., Guattari F. (1987) A Thousand Plateaus, Minneapolis: University of Minnesota Press; Beck U. (2016) The Metamorphosis of the World, Cambridge: Polity Press. 
COVID-19 pandemic and make the same mistake as in the past of trusting the market during the epidemic?

On the one hand, these are rather rhetorical questions with answers provided by the book despite the author's focus on the positive cases of overcoming the negative aspects of contemporary life. For instance, the current pandemic emphasized the duty of scientists and public intellectuals to freely contribute their ideas to the larger society. However, when the whole environment became virtual, experts became equal to non-experts in their ability to reach the public and to affect its representations and decisions due to the commercial interests and censorship prerogative of the major web channels and social media. Therefore, technology further undermined the expert status of scientists and public intellectuals, showing them as incapable of reducing uncertainty and predicting the next steps of the invisible enemy. The whole situation of uncertainty undermined our trust in policymakers, the ruling elites, and institutions at both the national and international levels as understanding no more than we do, as relying on the same expert opinions and estimates that we read in the media, and as ignoring individual rights and freedoms under the guise of the fight for our health and well-being in the "new social normality". ${ }^{11}$ Certainly, people are disappointed with the governments' failed promises of perfect decisions and predictable outcomes based on omnipotent science. However, the author's idea, that instead of "constructing and testing out a variety of scenarios", in the time of crisis, "most companies (and governments) work frantically to construct a single, perfect plan" and "shrink their options just when they need to expand them" (249), does not seem to be convincing since such a choice can be either enforced by objective limitations or justified by the expertise based on previous crisis management.

On the other hand, the author does not exaggerate the activist appeal of the book and does not call to an immediate action - there is rather an explanation of the need to think broader than one's private life, to develop (sociological) imagination in order not to be an object of manipulation for management and commercial reasons, and to strengthen one's free agency to influence public life.

11. See, e.g., Shelton T. (2020) A Post-truth Pandemic? Big Data \& Society, vol. 7, no 2; Robert R., KentishBarnes N., Boyer A. et al (2020). Ethical Dilemmas Due to the COVID-19 Pandemic. Annals of Intensive Care, vol. 10, no 84, pp. 19; Jamrozik E., Selgelid M. J. (2020) COVID-19 Human Challenge Studies: Ethical Issues. Lancet, vol. 20, no 8, pp. 198-203. 


\title{
Чрезмерная вера в предопределенность и ее публичных
} защитников в нелинейном мире неизвестности: причины и... еще причины

\author{
Ирина Трочук \\ Доктор социологических наук, профессор кафедры социологии, Российский университет дружбы \\ народов \\ Ведущий научный сотрудник, Центр фундаментальной социологии, Национальный исследовательский \\ университет «Высшая школа экономики» \\ Адрес: ул. Миклухо-Маклая, д. 6, Москва, Российская Федерация 117198 \\ E-mail: irina.trotsuk@yandex.ru
}

Рецензия на: Margaret Heffernan. Uncharted: How Uncertainty Can Power Change (London: Simon \& Schuster, 2021). 